\title{
A REGULARIZAÇÃO FUNDIÁRIA URBANA NA LEI No 13.465/2017: ANÁLISE DA ADEQUAÇÃO DE SEUS INSTRUMENTOS À POLÍTICA URBANA CONSTITUCIONAL
}

\author{
Clara Cirqueira de Souza* \\ Maria Tereza Fonseca Dias **
}

\section{RESUMO}

Este artigo trata da Política de Regularização Fundiária Urbana da Lei $n^{\circ} 13.465 / 2017$. A pesquisa analisou sua adequação na promoção de valores constitucionais referentes à Política Urbana. Os instrumentos previstos na lei - Legitimação Fundiária, Legitimação de Posse, Concessão de Uso Especial para fins de Moradia e Demarcação Urbanística - foram descritas utilizando-se de metodologia dogmático-jurídica comparativa a partir de dados primários e secundários. Apesar das deficiências da Lei na observância de valores constitucionais, o trabalho concluiu que seus instrumentos não devem ser descartados até que as melhores estratégias sejam editadas, pois podem alcançar alguns resultados positivos na política urbana.

PALAVRAS CHAVE: Regularização fundiária; Política urbana; Lei 13.465/2017; Cidade formal; Legitimação de Posse; Concessão de Uso Especial para fins de Moradia

\section{URBAN LAND REGULATION IN ACT N. 13.465/2017: ADEQUACY OF ITS INSTRUMENTS TO CONSTITUTIONAL URBAN POLICY}

\begin{abstract}
This paper concerns the Policy of Urban Land Regulation stemming from Act n. 13,465/2017. The research analyzes the adequacy of the Act in promoting constitutional values with respect to Urban Policy. The instruments instituted by the Act - Land-title Regularization, Legalization of Tenure, Grant for Special Use for Housing Purposes and Urban Land Demarcation - were described using comparative methodology, primary and secondary data. Despite of the Statutes shortcomings in attaining Constitutional values, the research concluded its instruments should not be discarded until best strategies are designed. They remain effective means to achieve some results in implementing urban constitutional policy.
\end{abstract}

KEY WORDS: Land-title regularization; urban constitutional policy; Formal cities; Legalization of Tenure, Grant for Special Use for Housing Purposes.

\footnotetext{
* Mestranda no Programa de Pós-graduação em Direito da Universidade Federal de Minas Gerais (PPGD/UFMG), sob a orientação da Prof ${ }^{a}$. Miracy Barbosa de Sousa Gustin, na área de estudo D-10 "As relações na cidade, a alteridade, o usufruto equitativo e o meio ambiente", da Linha 2 "Direitos Humanos e Estado Democrático de Direito: fundamentação, participação e efetividade". Graduada na mesma instituição em 2018/1. Advogada.

** Mestre e Doutora em Direito. Professora Associada do Departamento de Direito Público da UFMG e do Mestrado em Instituições Sociais, Direito e Democracia da FUMEC. Pesquisadora do CNPq.
} 


\section{INTRODUÇÃO}

A alteração do ordenamento jurídico sobre a questão fundiária realizado pela Medida Provisória $n^{\circ} 759$, de 22 de dezembro de 2016, consolidada na Lei no 13.465, de 11 de julho de 2017, é o objeto deste artigo. Para tanto, o estudo da Política de Regularização Fundiária no Brasil e dos parâmetros legais estabelecidos por ela, consonantes à Política Urbana constitucional, foram necessários para a compreensão e para a comparação dos instrumentos instaurados pelo novo ordenamento e os existentes anteriormente.

Este trabalho tem como referencial teórico a compreensão do caráter social implantado na Política Urbana determinada constitucionalmente, baseado no estudo da função social da propriedade urbana (ROLNIK, 2007, p. 8). Esse caráter da Política Urbana constitucional foi desenvolvido e consolidado no estabelecimento de diretrizes para essa política no art. $2^{\circ}$ do Estatuto da Cidade - Lei n ${ }^{\circ}$ 10.257, de 10 de julho de 2001. A partir desse diploma legal, foi delineada uma ordem legislativa urbanística nacional, com competência executória municipal por meio do Plano Diretor, conforme previsto no art. 182, caput, da Constituição Federal de 1988 (CF/1988).

Dentre as diretrizes da política urbana presentes no Estatuto da Cidade, está prevista, no art. $2^{\circ}$, XIV, a regularização fundiária. Em 2003, com a criação do Ministério das Cidades, foi proposto, pela primeira vez, um Plano Nacional de Regularização Fundiária, alinhando, dessa forma, em todo o território nacional, às diretrizes postas a partir da ordem constitucional urbanística, inclusive por meio do fortalecimento da autonomia municipal, conforme art. 30, I e VIII, da CF/1988 (GOUVÊA; RIBEIRO, 2014, p. 322). A regulamentação relativa à regularização fundiária urbana teve sua disposição específica na Lei $n^{\circ} 11.977$, de 7 de julho de 2009, na qual o Capítulo III disciplinava quais os instrumentos e os procedimentos devem ser obedecidos ao ser feita a regularização de uma área, o que determinou um ordenamento da matéria.

A edição da Medida Provisória ${ }^{\circ}$ 759/2016 rompeu com esse regramento, ao revogar completamente esse texto legislativo que tratava da regularização fundiária urbana e instaura uma nova ordem. Essa Medida Provisória foi convertida na Lei $\mathrm{n}^{\mathrm{o}} 13.465$, de 11 de julho de 2017, consolidando no ordenamento jurídico nacional novos instrumentos e procedimentos para ser feita a regularização fundiária urbana (ReUrb), conforme denominada na citada lei. 
Para a observação dos instrumentos instituídos pela Lei n ${ }^{\circ}$ 13.465/2017 em comparação ao ordenamento jurídico legislativo brasileiro relativo à regularização fundiária urbana, foi usada a metodologia dogmático-jurídica, de tipo descritivo, para a comparação com a legislação anterior, principalmente, em relação à Lei no 11.977/2009. Ademais, no desenvolvimento da pesquisa, o método de levantamento dos dados legislativos de forma comparativa foi essencial para a compreensão do rol normativo alterado pela Lei n $13.465 / 2017$.

Cabe ressaltar que a delimitação da Regularização Fundiária Urbana (ReUrb) como objeto específico a ser tratado dentre os demais explorados na Lei no 13.465/2017 deve-se à relevância temática urbana no espectro social atual. O Brasil majoritariamente urbano, que tem sua organização em centros urbanos médios a grandes metrópoles, tem esse ambiente como cenário dos conflitos fundiários que assolam o país. Assim, ainda que se entenda a importância e a necessidade de serem trabalhadas as questões concernentes à Amazônia Legal e à questão fundiária rural - também presentes na referida lei -, inclusive em diálogo com a questão urbana, faz-se o recorte temático para focalizar o trabalho.

Considerando o exposto, cabe ainda ser apontada a conjuntura política e social em que essa lei foi sancionada. A Lei $n^{\circ} 13.465 / 2017$ surgiu em meio a diversas outras mudanças legislativas no país, promovidas após o afastamento, em 12 de maio de 2016, e posterior impeachment, em 31 de agosto de 2016, da Presidenta Dilma Rousseff. Entre as transformações legislativas relevantes, destacam-se: a Emenda Constitucional n ${ }^{\circ}$ 95, de 2016, - que promoveu o congelamento do orçamento público nos 20 (vinte) anos seguintes; a Lei no 13.467, de 13 de julho de 2017, que realiza a alteração e flexibilização das normas da CLT; a Lei n ${ }^{\circ} 13.429$, de 31 de março de 2017, que permite a terceirização de algumas das atividades-fim do Estado; além das diversas tentativas de reforma da previdência. Assim, é necessário compreender que houve uma mudança de paradigma no âmbito legislativo, o qual, pela orientação dos instrumentos normativos citados, vai de encontro à perspectiva constitucional do modelo de bem-estar e justiça social. Em suma, deve ser analisada a influência dessa perspectiva na Lei ${ }^{\circ}$ 13.465/2017 e como trabalhar esse novo paradigma legal, que se mostra contrário às conquistas da reforma Urbana introduzidas na Constituição de 1988. Para tanto, foi efetuado o estudo dos instrumentos previstos na lei no que tange à Regularização Fundiária Urbana.

Os instrumentos para a regularização fundiária previstos na lei foram descritos utilizando-se de metodologia dogmático-jurídica comparativa, a partir de dados primários e secundários. Uma dificuldade encontrada no desenvolvimento da pesquisa foi a inexistência de 
bibliografia específica sobre a Lei $\mathrm{n}^{\circ}$ 13.465/2017. Dessa forma, o trabalho foi realizado a partir do estudo direto do texto legal para a compreensão de quais instrumentos haviam sido alterados e do impacto legislativo causado.

Assim, o objetivo central do trabalho foi compreender, a partir do processo de constitucionalização da Política Urbana da CR/1988 centrada na noção de função social da propriedade e da cidade, a adequação dos instrumentos de Regularização Fundiária da Lei no 13.465/2017. Dois foram os conteúdos centrais tratados para alcançar esse objetivo. O primeiro diz respeito aos fundamentos constitucionais da Política Urbana e, a seguir, foram descritos os instrumentos de Regularização, quais sejam: a legitimação fundiária, a legitimação de posse, a Concessão de Uso Especial para fins de Moradia (CUEM) e a demarcação urbanística. Esses conteúdos foram importantes para a análise da adequação da Lei no 13.465/2017 à diretriz da Política Urbana constitucional.

\section{A QUESTÃO URBANA E O PROCESSO CONSTITUINTE}

O processo de redemocratização brasileiro teve por marco a Assembleia Constituinte, que gerou o texto constitucional promulgado em 1988. A Constituição Federal de 1988 (CF/1988) ficou conhecida por "Constituição Cidadã" devido a esse processo, que se caracterizou pela intensa participação popular nas proposituras e, ainda, pelo retorno de pautas de cunho social (SCHWARCZ; STARLING, 2015, p. 488). Dentre essas pautas, tem notoriedade o retorno ao que seriam as estruturas apontadas no projeto das Reformas de Base, defendido pelo Presidente João Goulart antes do golpe civil-militar de 1964, tal como a reforma urbana.

A expansão do debate sobre o urbano se deu com o Fórum Nacional da Reforma Urbana (FNRU), em 1987, fundado na mobilização de setores acadêmicos (MARICATO, 2000, p. 143) e populares. A estruturação do movimento se deu em torno do debate acerca da desigualdade, conformada pelos processos de urbanização descontrolados que geraram periferias sociais e o que foi chamado de "cidade informal", que, muito além da própria informalidade territorial, se diferenciava da dita cidade formal pelo escasso acesso aos equipamentos públicos, o que aprofundou a desigualdade já existente.

As raízes acadêmicas desse movimento eram principalmente a Faculdade de Arquitetura e Urbanismo da Universidade de São Paulo (FAU/USP), devido à forte influência da obra de Henri Lefèbvre. Já a organização popular desse movimento, à época, formou-se, em parte, pelas 
pessoas removidas e realocadas nos planos advindos dos projetos do Banco Nacional de Habitação (BNH) durante os anos 1970 (ROLNIK, 2017, p. 241) e organizados por meio das Comunidades Eclesiais de Base (MARICATO, 2012, p.18). No decorrer desses projetos (BONDUKI, 2014, p. 65) fez-se a crítica da falta de planejamento urbano integrado para promoção de uma cidade menos desigual, o que delineou a noção de direito à cidade e função social da mesma, posteriormente desenvolvida no processo da Assembleia Constituinte e inseridos na Política Urbana da Constituição, descrita a seguir.

\subsection{A Política Urbana constitucional: funções sociais da cidade e a matriz fundiária}

A Política Urbana constitucional é o eixo norteador do que deve ser o desenvolvimento urbano no país (SILVA, 2010, p. 56), conforme art. 21, IX, da CF/1988, sendo caracterizada em uma base fundiária a partir da qual deve ser gerada a transformação econômica e social. Isso decorre do fato de o capítulo que disciplina a política urbana na $\mathrm{CF} / 1988$ estar dentro do título que trata "Da Ordem Econômica", devendo ser interpretada a partir dos parâmetros da Constituição Econômica instituída. A teoria adotada constitucionalmente busca um intermédio entre as teorias puras, tanto da função social quanto da propriedade absoluta, buscando, portanto, a proteção ao aspecto individual fundiário em consonância à perspectiva social da cidade como meio de convivência (PINTO, 2005, p.185). Trata-se, na visão de Giovani Clark e outros, de hermenêutica do normativismo-dirigente, que deve ser avaliada para a identificação da ideologia constitucionalmente adotada (CLARK; CORRÊA; PONTES, 2013, p. 269).

Nesse sentido, a compreensão da política urbana como política de estado, tendo em vista sua previsão constitucional, é essencial nesse estudo. A política de estado representa um modelo de sociedade, instituída constitucionalmente, que deve ser perseguida no planejamento de políticas públicas. Como política de estado a política urbana constitucional deve ser adotada pelos governos e não podem ir de encontro ao paradigma previsto constitucionalmente, comprometido com a justiça social (BANDEIRA DE MELLO, 2008, p. 780). Neste trabalho, portanto, o estudo e a análise da Lei no 13.465/2017 foram realizados à luz do paradigma da política urbana constitucional enquanto política de estado.

De forma geral, então, é possível compreender a função social da cidade como um dever de organização do território de forma a possibilitar a melhor integração coletiva do ambiente urbano, proporcionando a efetivação dos direitos fundamentais e sociais dos cidadãos. Assim, 
a abrangência das funções sociais da cidade não se limita apenas à função social da propriedade urbana mas se coadunam, posto que o cumprimento da segunda gerará o pleno desenvolvimento da primeira, conforme art. 182, caput e $\S 2^{\circ}$, da CF/1988.

Passa-se a análise de como deve ser uma Política de Regularização Fundiária em face a essa Política Urbana constitucional.

\subsection{A Regularização Fundiária Urbana em acordo à Política Urbana constitucional}

A regularização fundiária é instrumento de política pública (SECCHI, 2013, p. 4) ${ }^{1}$ para a formalização do solo urbano no âmbito fundiário. A formalização do solo urbano se caracteriza pela existência de uma cidade formal (FERNANDES, 2007, p. 21), em que teria sido feita a ordenação e planificação espacial do território. Esse instrumento cumpre com a finalidade, não apenas de promover a titulação da terra, mas também de inserção do sujeito em um meio que viabilize o exercício de direitos básicos e o gozo de uma vida digna (FERNANDES, 2010, p. 183). A necessidade da regularização e de políticas fundiárias que cumpram com a função social da cidade se faz devido à marginalização de estratos da sociedade que não estejam dentro da "cidade legal" (FERNANDES, 2007, p. 19). Nesse sentido, primeiro será analisado o que seria uma regularização fundiária, para em seguida ser feita a análise desse instrumento dentro da Política Urbana constitucional.

Primeiramente, cumpre salientar o porquê da necessidade de ser feita a regularização. Ao aludir isso presume-se que exista uma norma e que há algo fora da norma que deva ser regularizado. Quando essa regularização é fundiária, portanto, têm-se uma norma relativa a bens imóveis e um solo que não está de acordo com essa norma; ou seja, o solo ainda não se caracteriza como um bem, o que seria "Na compreensão jurídica, somente como bens podem ser compreendidas as coisas que tenham dono, isto é, as coisas apropriadas." (SILVA, 2013, p. 208). Dessa forma, o que se busca na regularização fundiária é a produção de bens a partir do solo, o que ocorrerá por meio da titulação de um bem imóvel. Todavia, é necessário que seja determinada as delimitações da coisa a qual se irá impor direitos reais. Esse processo de

\footnotetext{
${ }^{1}$ A ideia de política pública abordada é a trabalhada a partir do livro "Políticas Públicas: conceitos, esquemas de análise, casos práticos" de Leonardo Secchi (2013). Nessa obra, o autor destaca que a definição conceitual de política pública deve perpassar algumas questões sobre quem poderia elaborá-las; se omissão ou negligência poderiam ser políticas públicas; e, se somente políticas estruturantes se enquadrariam como tal. Dessa forma, o autor delineia a ideia de política pública na obra como diretriz elaborada para o tratamento de um problema tido como público. Essa diretriz deve ter centralidade normativa estatal e pode ser elaborada com a participação de demais atores sociais.
} 
delimitação das glebas de terras será feito por loteamento e, tendo a referência do lote, será realizada a titulação a quem seja direito (ALFONSÍN, 2007, p. 74).

No caso do solo urbano, há que ser feito no território uma ordenação para a divisão desses lotes, o que ocorrerá pelo planejamento do espaço urbano. Esse planejamento se constitui em uma lógica de configuração do espaço construída historicamente para promover a circulação de bens e serviços dentro do sistema capitalista (HARVEY, 2005, p. 201). Então, será feito para a produção de espaço que não se reduzirá ao loteamento, mas se construirá, inclusive pela delimitação de onde pode ser loteado e onde será utilizado para a circulação (COUTO, 1981, p. 58).

O processo de ordenação e criação da cidade formal se dará na determinação no território de ruas/avenidas e quarteirões/quadras ${ }^{2}$. Os quarteirões ou quadras são os territórios que poderão ser loteados e se destinarão a ser bem imóvel. Depreende-se disso que, para estar regular, o solo deve ter todas as delimitações espaciais feitas acima, conforme art. $2^{\circ}, \S 4^{\circ}$, da Lei n 6.766 , de 19 de dezembro de 1979, para assim poder ser feita a titulação do bem. Ao ser criada uma matrícula cartorária para o bem, pela qual será feita a titulação, a forma de identificação do mesmo será pela determinação do lote no quarteirão/quadra, da região, da rua/avenida que se tem a entrada (COUTO, 1981, p. 175).

Dessa forma, a regularização fundiária é necessária quando um território está ocupado, mas ou não se tem nenhum planejamento do mesmo, ou se tem o planejamento, mas não foi realizada a titulação. Em ambos os casos será reconhecido como cidade informal, vez que não está de acordo à formalidade fundiária determinada (MARICATO, 2000, p. 154). No Brasil, a cidade informal pode ser verificada, por exemplo, nas favelas, com uma ocupação não planejada do espaço, como também nos condomínios de lotes, em que, muitas vezes, se há um planejamento do espaço, mas não ocorre a titulação.

Para cada caso, as medidas de regularização serão diferentes, uma vez que em um caso deverá ser provida a estruturação organizacional para ser possível a titulação e, no outro, bastará a identificação dos lotes com seus ocupantes (ALFONSÍN, 2007, p.75). Na hipótese de ser

\footnotetext{
2 De acordo com a Lei $\mathrm{n}^{\circ}$ 6.766, de 19 de dezembro de 1979, de Parcelamento do Solo: Art. $7^{\circ}$. A Prefeitura Municipal, ou o Distrito Federal quando for o caso, indicará, nas plantas apresentadas junto com o requerimento, de acordo com as diretrizes de planejamento estadual e municipal: (I) - as ruas ou estradas existentes ou projetada, que compõem o sistema viário da cidade e do município, relacionadas com o loteamento pretendido e a serem respeitadas; (II) - o traçado básico do sistema viário principal; (III) - a localização aproximada dos terrenos destinados a equipamento urbano e comunitário e das áreas livres de uso público; [...]. (BRASIL, 1979).
} 
necessário prover a estruturação organizacional urbanística para a titulação, ainda que englobe um conjunto maior de medidas, a centralidade da questão será somente proprietária.

Assim, em segundo lugar, será apresentado a regularização fundiária em face da Política Urbana. Inicialmente, cumpre destacar que a regularização fundiária dos assentamentos de população de baixa renda foi inserida como diretriz da Política Urbana no art. $2^{\circ}$, XIV, da Lei $\mathrm{n}^{\mathrm{o}}$ 10.257, de 10 de julho de 2001 (Estatuto da Cidade). Porém, é necessário o estudo de como essa diretriz foi compreendida na ordem jurídica.

Para tanto, serão tratadas, nos parágrafos seguintes, as legislações que disciplinavam a regularização fundiária urbana antes da vigência da Lei $n^{\circ} 13.465 / 2017$, quais sejam: a Lei ${ }^{\circ}$ 11.952, de 25 de junho de 2009, e a Lei no 11.977, de 7 de julho de 2009.

A Lei $n^{\circ}$ 11.952/2009, em seu Capítulo III, dispõe sobre a regularização fundiária de ocupações em terras da União, o que ocorreria por meio da doação da terra ao Município que seria competente por conceder direito real de uso aos ocupantes. Já a Lei no 11.977/2009, conhecida por ser a Lei que institui o Programa Minha Casa Minha Vida, também em seu Capítulo III dispunha sobre a regularização fundiária de assentamentos urbanos, criando diversos institutos para a realização da regularização, como a demarcação urbanística ${ }^{3}$ e a legitimação de posse ${ }^{4}$ (respectivamente, art. 47, III e IV, da Lei $n^{\circ} 11.977 / 2009$ ), além disso dividindo os processos para regularização em regularização fundiária de interesse social e de interesse específico (respectivamente, art. 47, VII e VIII, da Lei n ${ }^{\circ} 11.977 / 2009$ ).

Essas leis sofreram grandes alterações pela Lei $n^{\circ} 13.465 / 2017$, incluindo a revogação do Capítulo referente à regularização fundiária da Lei nº 11.977/2009. Por ora, cabe analisar a base constitucional que se tinha nessas leis e como isso conformava um ordenamento jurídico centrado na diretriz da Política Urbana constitucional.

O que significa o ordenamento que disciplina a regularização fundiária estar em conformidade à Política Urbana constitucional? Em sentido amplo, isso implica em ir além da finalidade meramente fundiária, já explicitada, ou seja, aproximar a propriedade e sua função social, como expressão constitucional, do instrumento de regularização utilizado. No âmbito estrito, consiste em ampliar o uso do projeto de regularização fundiária para além da titulação e das medidas que a viabilizem, mas também promover o acesso a equipamentos públicos em

\footnotetext{
${ }^{3} \mathrm{O}$ art. 47, III, da Lei ${ }^{\circ} 11.977 / 2009$ conceitua a demarcação urbanística como o procedimento administrativo pelo qual o poder público, no âmbito da regularização fundiária de interesse social, demarca imóvel de domínio público ou privado, definindo seus limites, área, localização e confrontantes, com a finalidade de identificar seus ocupantes e qualificar a natureza e o tempo das respectivas posses.

${ }^{4} \mathrm{O}$ art. 47, IV, da Lei $n^{\circ} 11.977 / 2009$ conceitua a legitimação de posse como ato do poder público destinado a conferir título de reconhecimento de posse de imóvel objeto de demarcação urbanística, com a identificação do ocupante e do tempo e natureza da posse.
}

Rev. de Direito Urbanístico, Cidade e Alteridade | e-ISSN: 2525-989X | Goiânia | v. 5 | n. 1 | | p.83-103| Jan/Jun. 2019 
uma lógica de urbanização da área (GOUVÊA; RIBEIRO, 2014, p. 321), como buscou implantar o Programa Papel Passado ${ }^{5}$. Esse caráter restava claro no art. 48 da Lei $n^{\circ}$ 11.977/2009 que foi revogado pela Lei $\mathrm{n}^{\mathrm{o}}$ 13.465/2017.

No inciso II do artigo citado ${ }^{6}$, restava clara a ideia da coordenação da política fundiária urbana com os demais âmbitos de integração social, tais como políticas setoriais de habitação, de meio ambiente, de saneamento básico, de mobilidade urbana e de geração de emprego e renda (GOUVÊA; RIBEIRO, 2014, p. 321). No inciso I, por sua vez, a defesa da ampliação do acesso à terra urbanizada coadunava-se com a garantia constitucional de promoção da justiça social. Ademais, a presença da participação popular como requisito, de acordo com o inciso III do artigo citado, estava em convergência ao viés dado pelo Estatuto da Cidade - Lei $\mathrm{n}^{\mathrm{o}}$ 10.257, de 10 de julho de 2001 - no tocante ao planejamento urbanístico. Dessa forma, a existência de uma ordem jurídica urbanística constitucional restava clara, posto a base constitucional ser sempre respeitada e seguida nas legislações seguintes.

Por fim, esse paradigma constitucional também determinou a ampliação do conceito de regularização fundiária empregado no ordenamento jurídico, sendo, portanto, mantida a necessidade de criação de direitos reais sobre o território como centro, porém adotando também uma matriz social de efetivação de direitos. No mais, também se tinha uma valorização da garantia de direitos reais que não se limitavam à propriedade, como, por exemplo, a concessão de uso especial para fins de moradia inserida pela Medida Provisória 2.220, de 4 de setembro de 2001. Logo, com a apresentação do estudo de como seria uma regularização fundiária a partir do paradigma constitucional da Política Urbana, será feita a análise comparativa da Lei ${ }^{\circ}$ 13.465/2017 com as legislações que conformavam a ordem jurídica anterior a ela.

\subsection{A ordem jurídica urbanística constitucional e a regularização fundiária}

\footnotetext{
${ }^{5}$ O Programa Papel Passado foi instituído pelo Governo Federal em 2003, tendo coordenação da Secretaria Nacional de Política Urbana (SNPU). O programa, que tinha um caráter progressista e buscava a efetivação da Política Urbana constitucional, foi consolidado como Política Nacional de Regularização Fundiária. A Política Nacional de Regularização Fundiária é o mesmo mecanismo usado pela Lei 13.465/2017.

${ }^{6}$ Art. 48. Respeitadas as diretrizes gerais da política urbana estabelecidas na Lei no 10.257 , de 10 de julho de 2001, a regularização fundiária observará os seguintes princípios: [...] II - articulação com as políticas setoriais de habitação, de meio ambiente, de saneamento básico e de mobilidade urbana, nos diferentes níveis de governo e com as iniciativas públicas e privadas, voltadas à integração social e à geração de emprego e renda. (Revogado pela Lei $n^{\circ} 13.465$, de 2017).
} 
A legislação infraconstitucional em matéria urbanística, como já dito, teve como norte a concepção imposta pela Política Urbana constitucional. O desenvolvimento do ordenamento jurídico nesse sentido pode ter como marco inicial o Estatuto da Cidade, vez que foi a legislação que aperfeiçoou o que estava, em linhas gerais, na CF/1988 (ALFONSÍN, 2005, p. 3). O Estatuto da Cidade disciplina a Política Urbana constitucional, instituindo para isso diversos instrumentos e consolidando outros. O Plano Diretor, instrumento de assento constitucional nos termos do art. $182, \S 1^{\circ}$, da $\mathrm{CF} / 1988$, previsto como instrumento de planejamento e por meio do qual será determinada a função social da propriedade, é aprimorado pela noção de Gestão Urbana Democrática ${ }^{7}$ inserida nos arts. 43 a 45 do Estatuto da Cidade.

No que tange à regularização fundiária urbana, o Estatuto da Cidade a prevê como diretriz, no art. $2^{\circ}$, XIV, e como instrumento da Política Urbana, no art. $4^{\circ}$, V, alínea 'q', ambos do Estatuto de 2001. Na previsão como diretriz, é delimitada como a regularização dos assentamentos de população de baixa renda, demonstrando o caráter social que perpassa o diploma legal. Não há na lei, entretanto, a determinação de quais seriam os instrumentos de regularização fundiária, em que pese o assunto ser também abordado no Estatuto da Cidade nos dispositivos referentes a demarcação urbanística (art. $4^{\circ}, \mathrm{V}$, alínea 't'); ao direito de perempção (art. 26, I) e a transferência do direito de construir (art. 35, III). Ainda é importante destacar o art. 42-A, que faz a exigência da regularização fundiária nos planos diretores de áreas que tenham risco geológico de desabamento e afins.

Outra Lei que tem centralidade na construção dessa ordem jurídica urbanística a partir da Política Urbana da CF/1988 é a Lei n 11.977/2009. Essa lei instituiu o Programa Minha Casa Minha Vida (MCMV), programa do Governo Federal para construção de habitação de interesse social e que também dispõe sobre a regularização fundiária urbana. A Lei do MCMV, à época, inovou ao implementar a normatização nacional de como deveriam ser feitos os procedimentos de regularização fundiária de assentamentos urbanos no país (GOUVÊA; RIBEIRO, 2014, p. 334).

O Programa foi alvo de críticas e comparações ao BNH (ARANTES; FIX, 2009, p.19); contudo o MCMV também avançou em determinados aspectos, dentre eles em estabelecer regulamentações à regularização fundiária urbana (BONDUKI, 2014, p. 312). Essa previsão legal, à época, inovou com instrumentos para a regularização fundiária como a Concessão de Uso Especial para fins de Moradia (CUEM), que visava a estabilização de uma situação fática

\footnotetext{
${ }^{7}$ A Gestão Democrática da Cidade é o modelo de gestão municipal imposto no Estatuto da Cidade. Essa forma de gestão da cidade se efetiva pela participação direta da população visando uma melhor representação dos interesses dos habitantes da cidade nas políticas implementadas (FIORILLO, 2005, p. 114).

Rev. de Direito Urbanístico, Cidade e Alteridade | e-ISSN: 2525-989X | Goiânia | v. 5 | n. 1 | | p.83-103| Jan/Jun. 2019
} 
fundiária, ainda que em terreno público. Todavia, com a entrada em vigor da Lei nº 13.465/2017 e com a Medida Provisória 759, de 22 de dezembro de 2016, o Capítulo III da Lei no 11.977/2009, que tratava da regularização fundiária, foi completamente revogado. Com essa revogação, houve a implementação de uma nova política de regularização fundiária, descrita a seguir.

\section{REGULARIZAÇÃO FUNDIÁRIA E OS INSTRUMENTOS DA LEI No 13.465/2017}

A Lei $\mathrm{n}^{\circ} 13.465$, de 11 de julho de 2017, se originou da Medida Provisória $\mathrm{n}^{\mathrm{o}} 759$ (MP 759/2016), de 22 de dezembro de 2016. A tramitação da MP no 759/2016 começou em 14 de fevereiro de 2017 com o recebimento da medida na Câmara dos Deputados e a constituição de Comissão Mista para analisar a matéria. Durante seu trâmite, foram propostos 732 (setecentos e trinta e duas) emendas, sendo consolidado o texto no Projeto de Lei de Conversão (PLV) $n^{\circ}$ 12, de 2017. O PLV n 12, de 2017, foi consolidado em 4 de maio de 2017, sendo submetido ao trâmite legislativo na Câmara dos Deputados e no Senado Federal. A sanção do referido PLV e transformação na Lei $n^{\circ} 13.465$ ocorreu em 11 de julho com uma série de vetos presidenciais, conforme Mensagem $n^{\circ} 232$, expedida da mesma data.

Do ponto de vista material, a Lei $n^{\circ} 13.465 / 2017$ dispõe acerca da regularização fundiária urbana e agrária, dos créditos concedidos para reforma agrária, da regularização fundiária na Amazônia Legal e da alienação de imóveis da União. A abrangência material da Lei gera alterações em 27 outros diplomas legais, o que demonstra o seu impacto normativo, como também a complexidade em se analisar e compreender todos os aspectos mudados. Por isso, neste trabalho foi realizado o recorte da análise em relação à Regularização Fundiária Urbana (ReUrb), mas entendendo que os demais campos atingidos pela lei também são de grande importância, inclusive, destacando-se a necessidade de se pensar de forma conjunta todo o impacto da nova legislação. Logo, passa-se ao estudo da ReUrb, seus intrumentos e seus procedimentos, conforme o disposto na Lei ${ }^{\circ} 13.465 / 2017$.

\subsection{A Regularização Fundiária Urbana (ReUrb) na Lei no 13.465/2017}

O Título II da Lei $\mathrm{n}^{\circ}$ 13.465/2017 (art. $9^{\circ}$ a 82), divide-se em 11 (onze) capítulos: (I) Disposições Gerais; (II) Dos instrumentos da ReUrb; (III) Do procedimento administrativo; (IV) Do Registro da Regularização Fundiária; (V) Do Direito Real de Laje; (VI) Do 
Condomínio de Lotes; (VII) Dos Conjuntos Habitacionais; (VIII) Do Condomínio Urbano Simples; (IX) Da Arrecadação de Imóveis Abandonados; (X) Da Regularização da Propriedade Fiduciária do Fundo de Arrendamento Residencial - FAR; (XI) Disposições Finais e Transitórias.

Antes da análise específica dos instrumentos da da Lei 13.465/2017, destacam-se alguns pontos inovadores no tocante à ReUrb.

O Capítulo VII (art. 59 e 60) trata da regularização como conjunto habitacional, que ocorrerá no caso do núcleo urbano informal estar constituído em imóvel, público ou privado, edificado para alienação de unidades. No caso de ocupação em prédios nas áreas centrais, prática relativamente comum dos movimentos por moradia urbana, se, por exemplo, o prédio ocupado tenha sido construído para a alienação das unidades, poderá ser regularizada titulando os ocupantes reconhecidos, sem necessidade de habite-se, e, ainda, no caso de ser ReUrb-S são dispensadas as certidões de quitação tributária e afins. Todavia, no $\S 2^{\circ}$, do art. 59 , da Lei ${ }^{\circ}$ 13.465/2017, é colocada uma ressalva para a efetivação da ReUrb que não resta clara, vez que estabelece que "[...] o ente público promotor do programa habitacional demonstrar que, durante o processo de regularização fundiária, há obrigações pendentes [...]" (BRASIL, 2017) as unidades serão atribuídas ao ente. A não definição de quais seriam as obrigações pendentes que justificariam tal ato do ente público permite arbitrariedades e a não consolidação da ReUrb.

Já no Capítulo VII (arts. 61 a 63) é disciplinado o condomínio urbano simples dentro da ReUrb. As disposições relativas ao condomínio edilício constantes do Código Civil de 2002 são predominantes neste capítulo, equiparando-se, assim, o condomínio constituído na ReUrb com os demais.

O Capítulo IX (arts. 64 e 65) aborda a arrecadação de imóveis abandonados para fins de $\operatorname{ReUrb}^{8}$ e prevê a arrecadação do imóvel em que tenha cessado os atos de posse e haja inadimplência tributária por mais de 05 (cinco) anos. Por fim, o Capítulo X (arts. 66 e 67) trata da regularização da propriedade fiduciária do Fundo de Arrendamento Residencial - FAR, que se refere às propriedades que estão em garantia fiduciária junto ao FAR. Nesse Capítulo, foram alterados dispositivos da Lei 11.977/2009 e da Lei 9.514, de 20 de novembro de 1997, vez que é tema que se vincula a financiamento imobiliário, principalmente, do Programa Minha Casa Minha Vida. Destacados esses pontos inovadores da lei, passa-se a análise dos instrumentos específicos da Reurb introduzidos pela Lei 13.465/2017.

\footnotetext{
${ }^{8}$ A arrecadação deverá ocorrer nos termos do art. 1.276 do Código Civil de 2002. Ainda está em conformidade ao disposto no art. $7^{\circ}$ do Estatuto da Cidade e na Política Urbana, art. 182, §4º , II, da CF/1988. 


\subsection{Dos instrumentos da ReUrb na Lei $n^{\circ}$ 13.465/2017}

A ReUrb se destina à identificação e incorporação dos núcleos urbanos informais à cidade formal, bem como à titulação dos ocupantes, de acordo com art. $9^{\circ}$ da Lei $n^{\circ}$ 13.465/2017. Para que seja realizada a regularização, então, são previstos diversos instrumentos que serão empregados objetivando a satisfação da ReUrb, tais como: (I) a legitimação fundiária e a legitimação de posse; (II) a usucapião; (III) a desapropriação em favor dos possuidores; (IV) a arrecadação de bem vago; (V) o consórcio imobiliário; (VI) a desapropriação por interesse social; (VII) o direito de preempção; (VIII) a transferência do direito de construir; (IX) a requisição, em caso de perigo público iminente; (X) a intervenção do poder público em parcelamento clandestino ou irregular; (XI) a alienação de imóvel pela administração pública diretamente para seu detentor; (XII) a concessão de uso especial para fins de moradia; (XIII) a concessão de direito real de uso; (XIV) a doação; e, (XV) a compra e venda.

De todos esses instrumentos, somente os previstos no inciso (I) - a legitimação fundiária e a legitimação de posse - serão objeto de análise.

A legitimação fundiária é instituto jurídico criado na Lei no $13.465 / 2017$ e inova no ordenamento jurídico, uma vez que é "mecanismo de reconhecimento da aquisição originária do direito real de propriedade", nos termos do art. 11, VII, da referida lei. Essa inovação decorre do fato de ser forma de aquisição originária da propriedade - o que anteriormente seria possível apenas por meio da usucapião.

A similaridade dos institutos da usucapião e da legitimação fundiária, contudo, se limita à forma de aquisição originária. Primeiramente, cumpre explicar que a aquisição originária de propriedade consiste na abertura de nova matrícula para o imóvel, desvinculando-o de seu histórico de transferências. A especificidade da usucapião está exatamente nessa desvinculação, que seria possível pela perda de quaisquer direitos de gozo da propriedade sobre a coisa pelo proprietário, pois não teria tido os cuidados devidos com o bem. Ademais, o imóvel seria adquirido sem qualquer impedimento, restrição ou dívida anterior, por isso é necessário que sejam estabelecidos critérios rígidos para a conformação da possibilidade da usucapião e de procedimento judicial especializado para tanto.

Por outro lado, a legitimação fundiária é conferida por ato do poder público exclusivamente no processo da ReUrb, conforme art. 23 da Lei no 13.465/2017. Ainda que tenha a especificidade de estar circunscrita à ReUrb, é incomum o fato de o único critério para a

Rev. de Direito Urbanístico, Cidade e Alteridade | e-ISSN: 2525-989X | Goiânia | v. 5 | n. 1 | | p.83-103| Jan/Jun. 2019 
legitimação fundiária é ser ocupante de núcleo urbano informal consolidado até 22 de dezembro de $2016^{9}$. Cabe destacar a discussão da constitucionalidade da legitimação fundiária em terra pública, prevista nos art. 23 , caput e $\S 4^{\circ}$, e art. 24 da lei, face a vedação expressa na CF/1988 à usucapião em terreno público no art. $183, \S 3^{\circ}$ promovida pelo Instituto de Arquitetos do Brasil (IAB) na Ação Direta de Inconstitucionalidade (ADI) 5883, sem decisão até a presente data. ${ }^{10}$

Mesmo não estando disposto expressamente na parte da Regularização Fundiária Urbana da Lei $n^{\circ} 13.465 / 2017$, há que se destacar a facilitação promovida no que tange à alienação de imóveis pertencentes à União. As alterações previstas no Título III - Dos procedimentos de avaliação e alienação de imóveis da União da Lei n 13.465/2017 incidem especialmente sobre a Lei no $11.952 / 2009$, a qual, junto da Lei $n^{\circ} 11.977 / 2009$, é a que sofreu maiores interferências.

A possibilidade de regularização fundiária em terras públicas é o tema de maior divergência entre os estudiosos. Isso decorre do fato de que, ao mesmo tempo em que se possibilita a regularização das ocupações que lutam pelo direito à moradia, garantindo o acesso à terra dessa população, pode implicar, em outras situações fáticas, à dilapidação do patrimônio público. Ainda, há a possibilidade desse patrimônio ser apropriado, produzindo maior concentração fundiária, tendo sido a Lei $\mathrm{n}^{\circ}$ 13.465/2017, nesse aspecto, ter sido denominada como "lei da grilagem".

Nesse sentido, deve ser retomado o instituto previsto no inciso (XII) do art. $9^{\circ}$, da Lei $\mathrm{n}^{\mathrm{o}}$ 13.465/2017, qual seja, a concessão de uso especial para fins de moradia - CUEM. Esse instituto já era previsto no ordenamento urbanístico e considerado instrumento progressista de regularização fundiária de imóveis públicos, vez que, sem recorrer à propriedade, busca garantir direito à moradia. A CUEM permanece no ordenamento jurídico com a redação dada ao art. 70 da Lei $n^{\circ}$ 13.465/2017. Contudo, a dificuldade que resta desse instrumento é qual será sua aplicabilidade frente à possibilidade da legitimação fundiária. Com a análise dos dispositivos, depreende-se que a CUEM se limitará aos casos em que (1) o imóvel público não seja objeto de ReUrb; (2) o núcleo urbano informal em que está o imóvel público não era consolidado em 22 de dezembro de 2016, mesmo que ocupado há 5 (cinco) anos à época.

Raciocínio semelhante é desencadeado ao analisar a legitimação de posse. O instituto previsto no art. 25 da Lei $\mathrm{n}^{\mathrm{o}}$ 13.465/2017 é gerador de título de direitos reais para garantia da

\footnotetext{
${ }^{9}$ A data de sanção da MP759/2016 foi utilizada como parâmetro na Lei 13.465/2017 para limitação das ocupações que possam ser regularizadas.

${ }^{10}$ A Lei no 13.465/2017 gerou três Ações Diretas de Inconstitucionalidade (ADI) no Supremo Tribunal Federal (STF). Nessas ações são impugnados diversos dispositivos da Lei $n^{\circ} 13.465 / 2017$, sob o fundamento de inconstitucionalidades formais e materiais da referida lei.
} 
posse com circunscrição exclusiva na ReUrb. A diferença entre a legitimação de posse e a legitimação fundiária, para além do direito real garantido, é o fato da primeira não poder ocorrer em área pública, conforme art. $25, \S 2^{\circ}$, da lei citada. Todavia, a legitimação de posse poderá ser convertida em título de propriedade, o que, para ocorrer, deverá ser cumprido os critérios relativos à usucapião constitucional do art. 183 da CF/1988 e a conversão ocorrerá como aquisição originária também, mas por ato do poder público. Dessa forma, verifica-se que a legitimação de posse mescla critérios da legitimação fundiária e da usucapião constitucional. Ainda se destaca o fato do título constituído pela legitimação de posse, mesmo não sendo de propriedade, é passível de transferência, nos termos do $§ 1^{\circ}$, do art. 25, da Lei $n^{\circ}$ 13.465/2017.

O Quadro 1 ilustra a comparação entre a CUEM, a Legitimação Fundiária e a Legitimação de Posse dentro da ReUrb:

\section{QUADRO 1}

\section{SISTEMATIZAÇÃO DOS INSTRUMENTOS A SEREM APLICADOS EM FACE À SITUAÇÃO FÁTICA}

\begin{tabular}{|c|c|c|}
\cline { 2 - 3 } \multicolumn{1}{c|}{} & $\begin{array}{c}\text { Núcleo urbano informal } \\
\text { consolidado }\end{array}$ & Núcleo urbano informal \\
\hline IMÓVEL PÚBLICO & Legitimação Fundiária & Legitimação de Posse \\
\hline IMÓVEL PRIVADO & $\begin{array}{c}\text { Legitimação Fundiária/ } \\
\text { Legitimação de Posse }\end{array}$ & \\
\hline
\end{tabular}

Fonte: Lei no 13.465/2017 <http://www.planalto.gov.br/ccivil_03/_ato2015-2018/2017/lei/l13465.htm>

Por último, trata-se da demarcação urbanística, instrumento que não está previsto no rol do art. 15 da Lei $n^{\circ}$ 13.465/2017, vez que não ocorre dentro do processo da ReUrb, nos termos do art. $31, \S 9^{\circ}$, da Lei $n^{\circ} 13.465 / 2017$. A demarcação urbanística, assim como a CUEM e a legitimação de posse, foi inicialmente prevista na Lei $\mathrm{n}^{\circ}$ 11.977/2009. O procedimento, como definido no art. 19 da Lei no 13.465/2017, se destina à identificação e delimitação dos imóveis irregulares com seus respectivos ocupantes para realização da titulação. Os procedimentos da demarcação urbanística, conforme previsto no art. 19, §3º da Lei $n^{\circ} 13.465 / 2017$, não constituem condição para o processamento e a efetivação da Reurb. Ou seja, a demarcação urbanística pode ocorrer ainda que não tenha uma política de regularização fundiária para a área. Esse procedimento, portanto, pode ser utilizado para a regularização fundiária individualmente, via administrativa, independente da regularização da totalidade da área, nos termos do art. $22, \S 6^{\circ}$ da referida lei. 


\section{CONCLUSÃO}

A Lei $\mathrm{n}^{\mathrm{o}}$ 13.465, de 11 de julho de 2017, suscitou debates diversos, devido às matérias disciplinadas, mas, principalmente, pela forma como foi editada. No caso da lei citada, o fato de ser originária de uma Medida Provisória - que não permite participação popular na construção da lei - bem como da falta de diálogo com os meios acadêmicos e os fóruns que se destinam ao estudo das questões urbanas, provocou forte rejeição a esse instrumento normativo. Perpassar o estranhamento inicial para com a lei, visando a realização de um estudo técnico e à compreensão profunda desse novo ordenamento, foi um desafio para a construção deste trabalho.

A singularidade alcançada com o conjunto normativo urbanístico existente anterior à MP n $n^{\circ} 759 / 2016$ e decorrente da Política Urbana constitucional promovia segurança jurídica e possibilitava que a população tivesse maior clareza e aproximação dos mecanismos de regularização fundiária. A manutenção da segurança jurídica para a utilização desses instrumentos é de extrema importância, inclusive para o reconhecimento, por parte da população, da legitimidade das instituições do Estado. Por isso há que ser questionada a urgência em que se justificou a edição da MP nº 759/2016.

Outra questão correlata à já exposta ao longo do trabalho é a forma que a MP e, sucessivamente, a Lei $\mathrm{n}^{\mathrm{o}}$ 13.465/2017 tratou a matéria, sem qualquer diálogo com os demais instrumentos normativos existentes. O aspecto notável da falta de diálogo das fontes normativas é ter sido produzido conteúdo normativo urbanístico e de regularização fundiária urbana sem qualquer menção ao Plano Diretor, previsto no art. 182, §1 $1^{\circ}$ da CF/1988 como instrumento básico da política urbana. Além disso, diferentemente do instituído na Lei n 11.977/2009, em que a regularização fundiária se orientava pelas diretrizes da Política Urbana, com previsões específicas práticas para efetividade da lei, a Lei ${ }^{\circ}$ 13.465/2017 - ainda que tenha tratado da observância das diretrizes constitucionais, em seu art. 10 - trataram as políticas e instrumentos de regularização fundiária com viés puramente voltado à titulação e não à promoção da justiça social.

Essa perspectiva da regularização fundiária centrada na titulação e criação de mais propriedades é política pública de incentivo ao mercado e à comercialização da propriedade urbana; política essa contrária à valorização e fortalecimento da posse e do valor de uso desses bens. Assim, a realidade fática das cidades e do exercício do direito à moradia ficam submetidas à consagração da propriedade e do registro cartorário dos terrenos, o que impulsiona a crítica à 
Lei $\mathrm{n}^{\circ}$ 13.465/2017, por incentivar a criação das chamadas "cidades de papel". As "cidades de papel" se caracterizam pela valorização extremada do título/do papel, sendo construídas políticas pautadas somente na adequação ao papel e não à promoção de uma vida digna aos cidadãos.

A defesa de uma forma alternativa de ordenação espacial e sem vinculação direta e necessária à titulação em propriedade privada zelando pela primazia de um bem-estar coletivo e uma cidade menos desigual, é essencial perante a conjuntura em que editada a Lei $n^{\circ}$ $13.465 / 2017$.

No mais, há que ser enaltecido o fato da inserção do direito real de laje ter ocorrido por meio da lei em tela. A possibilidade vislumbrada de facilitação dos procedimentos de regularização e, principalmente, da regularização em terra pública também poderá favorecer os movimentos de luta por moradia. Todavia, a problemática da alienação de terras públicas, com o desfazimento do patrimônio público e a probabilidade de concentração fundiária, é um efeito da lei que não pode ser desprezado. A dubiedade desses instrumentos deve ser esclarecida e ponderada, tendo em vista ser essa a legislação que será aplicada nos próximos anos.

Conclui-se, portanto, que a Lei $n^{\circ} 13.465 / 2017$ inaugura uma nova ordem normativa urbanística que se distancia da ordem constitucional. Isso é demonstrado no afastamento para com o paradigma constitucional vigente, ainda que não tenha ocorrido a ruptura com a Política Urbana constitucional, as modificações implantadas na lei pautam a titulação - ou seja, a formação de bens imóveis - em detrimento de uma perspectiva de integração social no espaço urbano. Dessa forma, ainda que possa obter resultados que atendam a demandas sociais procedentes da Lei ${ }^{\circ}$ 13.465/2017, não deveria ser esse o viés incutido na norma.

Apesar das deficiências da Lei na observância de valores constitucionais, o trabalho concluiu que seus instrumentos não devem ser descartados até que as melhores estratégias sejam projetadas, pois podem alcançar alguns resultados da política urbana.

Em suma, tendo em vista ser o instrumento legislativo que terá aplicabilidade, faz-se necessária a apropriação dos conceitos, institutos e procedimentos dispostos na Lei $\mathrm{n}^{\circ}$ 13.465/2017. Essa apropriação deve se dar a partir da compreensão da totalidade da lei, o que este trabalho pretendeu contribuir no tocante à Regularização Fundiária Urbana. Logo, no caso da ReUrb, com a compreensão dos instrumentos previstos, a apropriação desses se dará na vinculação desses aos valores da Política Urbana constitucional para sua aplicação, objetivando a produção do espaço para impulsão da justiça social por meio do acesso à cidade. 


\section{REFERÊNCIAS}

ALFONSÍN, Betânia. Depois do Estatuto da Cidade: ordem jurídica e política urbana em disputa - Porto Alegre e o Urbanizador Social. Revista brasileira de estudos urbanos e regionais, v.7, $\mathrm{n}^{\circ}$. 2 .2005. Disponível em: <http://rbeur.anpur.org.br/rbeur/article/view/144>. Acesso em: 26/06/2018.

ALFONSÍN, Betânia. O significado do Estatuto da Cidade para os processos de regularização fundiária no Brasil. In: ROLNIK, Raquel. (et al.) Regularização fundiária sustentável conceitos e diretrizes. Brasília/DF: Ministério das Cidades, 2007.

ARANTES, Pedro Fiori; FIX, Mariana. 'Minha casa, minha vida', o pacote habitacional de Lula. Correio Cidadania, publicado dia 30/07/2009. Disponível em: < http://www.correiocidadania.com.br/especiais/66-pacote-habitacional/3580-31-07-2009minha-casa-minha-vida-o-pacote-habitacional-de-lula>. Acesso em: 26/06/2018.

BANDEIRA DE MELlO, Celso Antônio. Curso de Direito Administrativo. 25 ed. São Paulo: Malheiros, 2008.

BRASIL. Lei $n^{\circ}$ 6.766, de 19 de dezembro de 1979. Dispõe sobre o Parcelamento do Solo Urbano e dá outras Providências. Disponível em:

<http://www.planalto.gov.br/ccivil_03/Leis/16766.htm>. Acesso em: 09/06/2018.

BRASIL. Constituição (1988). Constituição da República Federativa do Brasil. Brasília/DF: Senado Federal: Centro Gráfico, 1988.

BRASIL. Lei 10.257, de 10 de julho de 2001 - Estatuto da Cidade. Regulamenta os arts. 182 e 183 da Constituição Federal, estabelece diretrizes gerais da política urbana e dá outras providências. Disponível em:

<http://www.planalto.gov.br/ccivil_03/leis/LEIS_2001/L10257.htm>. Acesso em: 09/06/2018.

BRASIL. Medida Provisória $n^{\circ} 2.220$, de 04 de setembro de 2001. Dispõe sobre a concessão de uso especial de que trata o $\S 1^{\circ}$ do art. 183 da Constituição, cria o Conselho Nacional de Desenvolvimento Urbano - CNDU e dá outras providências. Disponível em:

<http://www.planalto.gov.br/ccivil_03/mpv/2220.htm>. Acesso em: 09/06/2018.

BRASIL. Lei no 10406, de 10 de janeiro de 2001 - Código Civil. Institui o Código Civil. Disponível em: <http://www.planalto.gov.br/ccivil_03/Leis/2002/110406.htm>. Acesso em: 09/06/2018.

BRASIL. Lei $n^{\circ} 11.952$, de 25 de junho de 2009. Dispõe sobre a regularização fundiária das ocupações incidentes em terras situadas em áreas da União, no âmbito da Amazônia Legal. Disponível em: <http://www.planalto.gov.br/ccivil_03/_ato2007-2010/2009/lei/111952.htm>. Acesso em: 09/06/2018.

BRASIL. Lei 11.977, de 07 de julho de 2009. Dispõe sobre o Programa Minha Casa, Minha Vida - PMCMV e a regularização fundiária de assentamentos localizados em áreas urbanas. Disponível em: < http://www.planalto.gov.br/ccivil_03/_ato2007-2010/2009/lei/111977.htm>. Acesso em: 20/06/2017. 
BRASIL. Medida Provisória $n^{\circ} 759$, de 22 de dezembro de 2016. Dispõe sobre a regularização fundiária rural e urbana, sobre a liquidação de créditos concedidos aos assentados da reforma agrária e sobre a regularização fundiária no âmbito da Amazônia Legal, institui mecanismos para aprimorar a eficiência dos procedimentos de alienação de imóveis da União, e dá outras providências. Disponível em: <https://legis.senado.leg.br/sdleggetter/documento?dm=5347838\&disposition=inline >. Acesso em: 20/06/2017.

BRASIL. Lei $n^{o} 13.465$, de 11 de julho de 2017. Dispõe sobre a regularização fundiária rural e urbana, sobre a liquidação de créditos concedidos aos assentados da reforma agrária e sobre a regularização fundiária no âmbito da Amazônia Legal; institui mecanismos para aprimorar a eficiência dos procedimentos de alienação de imóveis da União. Disponível em: < http://www.planalto.gov.br/ccivil_03/_ato2015-2018/2017/lei/113465.htm>. Acesso em: 09/06/2018.

BRASIL, Congresso Nacional. Projeto de Lei de Conversão (PLV) $n^{o} 12$, de 2017. Projeto originário da Medida Provisória $n^{\circ} 759$ de 2016. Disponível em: < http://www.camara.gov.br/proposicoesWeb/prop_mostrarintegra?codteor=1553435\&filename $=\mathrm{PLV}+12 / 2017+\mathrm{MPV75916+ \% 3D \% 3E+MPV+759/2016>.} \mathrm{Acesso} \mathrm{em:} \mathrm{09/06/2018.}$

BRASIL, Supremo Tribunal Federal. Ação Direta de Inconstitucionalidade $n^{\circ} 5883$ (ADI 5883). Relator: Luiz Fux. Brasília/DF: 2017. Disponível em: <http://portal.stf.jus.br/processos/detalhe.asp?incidente=5342200 >. Acesso em: 26/06/2018.

BONDUKI, Nabil. Avanços, limitações e desafios da política habitacional do Governo Lula. In: FERNANDES, Edésio; ALFONSÍN, Betânia. Direito à moradia adequada: o que é, para quem serve, como defender e efetivar. Belo Horizonte/MG: Editora Fórum, 2014.

BONDUKI, Nabil. Os pioneiros da habitação social: cem anos de política pública no Brasil vol. 1. São Paulo/SP: Editora Unesp, 2014.

CLARK, Giovanni; CORRÊA, Leonardo Alves; NASCIMENTO, Samuel Pontes do. Ideologia constitucional e pluralismo produtivo. Revista da Faculdade de Direito da UFMG, Número Especial em Memória do Prof. Washington Peluso, p. 265 - 300. Belo Horizonte/MG: 2013.

COUTO, Sérgio A. Frazão do. Manual Teórico e Prático do Parcelamento Urbano. 1 ed. Rio de Janeiro/RJ: Ed. Forense, 1981.

FERNADES, Edésio. Regularização de assentamentos informais: o grande desafio dos municípios, da sociedade e dos juristas brasileiros. In: ROLNIK, Raquel. (et al.) Regularização fundiária sustentável - conceitos e diretrizes. Brasília/DF: Ministério das Cidades, 2007.

FERNANDES, Edésio. Desafios da regularização fundiária de assentamentos informais consolidados em áreas urbanas. Fórum de Direito Urbano e Ambiental, Belo Horizonte/MG, v. 9, n. 49, jan. 2010. Disponível em: <http://bdjur.stj.jus.br/dspace/handle/2011/28192>. Acesso em: 20/06/2017.

FERRARI, Terezinha. Fabricalização da cidade e ideologia da circulação. 2 ed. - São Paulo/SP: Outras Expressões, 2012. 
FIORILlO, Celso Antônio Pacheco. Estatuto da Cidade comentado. 2 ed., rev.atual. ampl. São Paulo/SP: Revista dos Tribunais, 2005.

FÓRUM SOCIAL MUNDIAL (FSM). Carta Mundial do Direito à Cidade. Documento produzido a partir do Fórum Social Mundial Policêntrico de 2006. Caracas/Venezuela; Carachi/Paquistão; e, Bamako/Mali: 2006. Disponível em:

<http://www.polis.org.br/uploads/709/709.pdf>. Acesso em: 09/06/2018.

GOUVÊA, Denise de Campos; RIBEIRO, Sandra Bernardes. A Política Nacional de Regularização Fundiária - Programa Papel Passado. In: FERNANDES, Edésio; ALFONSÍN, Betânia. Direito à moradia adequada: o que é, para quem serve, como defender e efetivar. Belo Horizonte/MG: Editora Fórum, 2014.

HARVEY, David. A produção capitalista do espaço urbano. Trad.: Carlos Slack.1 ed. - São Paulo/SP: Annablume, 2005.

MARICATO, Ermínia. As ideias fora do lugar e o lugar fora das ideias. In: ARANTES, Otília; VAINER, Carlos; MARICATO, Ermínia. A cidade do pensamento único: desmanchando consensos. Petrópolis/RJ: Vozes, 2000.

MARICATO, Ermínia. O impasse da Política Urbana no Brasil. 2 Ed.- Petrópolis/RJ: Vozes, 2012.

PINTO, Victor Carvalho. Direito Urbanístico: Plano Diretor e Direito de Propriedade. São Paulo/SP: Editora Revista dos Tribunais, 2005.

ROLNIK, Raquel. Apresentação Geral - Curso a distância em regularização fundiária de assentamentos informais urbanos. In: ROLNIK, Raquel. (et al.) Regularização fundiária sustentável - conceitos e diretrizes. Brasília /DF: Ministério das Cidades, 2007.

ROLNIK, Raquel. Das lutas pela reforma urbana às cidades da Copa do Mundo. Artigo publicado originalmente em mesa-redonda do XIV Encontro Nacional de Pós Graduação e Pesquisa em Planejamento Urbano e Regional. In: ROLNIK, Raquel. Territórios em conflito: São Paulo: Espaço, história e política. São Paulo/SP: Editora Três Letras, 2017.

SCHWARCZ, Lilia Moritz; STARLING, Heloisa Murgel. Brasil: uma biografia. 1 ed., 5 reimpr. - São Paulo/SP: Companhia das Letras, 2015.

SECCHI, Leonardo. Políticas Públicas: conceitos, esquemas de análise, casos práticos. 2 ed. São Paulo/SP: Cengage Learning, 2013.

SILVA, José Afonso da. Direito Urbanístico Brasileiro. 6 ed. rev. atual. São Paulo/SP: Malheiros Editores, 2010.

SILVA, De Plácido e. Vocabulário Jurídico. Atual.: Nagib Slaibi Filho e Priscila Pereira Vasques Gomes. 30 ed. Rio de Janeiro/RJ: Editora Forense, 2013. 
